The word that is resolved on the way

\title{
La palabra que se resuelve en el camino
}

\author{
María del Carmen Lara Nieto \\ Universidad de Granada. Departamento de Filosofía II \\ larnieto@ugr.es \\ DOI: https://doi.org/10.15366/bp.2020.24.003 \\ Bajo Palabra. II Época. No 24. Pgs: 55-72
}

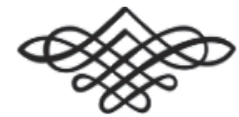


Recibido: 28/07/2020

Aprobado: $12 / 08 / 2020$

\section{Resumen}

Sobre el exilio desde el sin sentido, del abandono y la soledad que suscita encontrarse fuera de la propia patria o en cualquier situación derivada del absurdo de la condición humana. Esta aportación es una reflexión sobre la reivindicación que María Zambrano hace del exilio español para poder afirmar que el exilio es el lugar privilegiado para el conocimiento de sí misma y el descubrimiento de la propia patria.

Palabras clave: exilio, soledad, abandono, libertad, absurdo.

\section{Abstract}

On the exile from the nonsense, abandonment and loneliness that arises from being outside the homeland or in any situation derived from the absurdity of the human condition. This contribution is a reflection on the claim that María Zambrano makes of Spanish exile to be able to affirm that exile is the privileged place for self-knowledge and the discovery of one's homeland.

Keywords: exile, loneliness, abandonment, freedom, absurdity. 
"De destierro en destierro, en cada uno de ellos el exiliado va muriendo, desposeyéndose, desenraizándose... Y puede quedarse tan sólo alli donde pueda agonizar libremente, ir meciéndose al mar que se revive, estar despierto sólo cuando el amor que le llena se lo permite, en soledad y libertad"

(María Zambrano, Los bienaventurados)

\section{Introducción}

UNA FILOSOFí́ ATÍPICA, así podemos valorar por su nuevo método «razón poética», para avanzar en la reflexión intelectual y cotidiana espacio donde afronta la existencia María Zambrano, creando una puerta de esperanza y de humanización en el contexto de una filosofía que piensa la vida. Sus textos ofrecen un mundo de conexiones, siendo el exilio la línea roja que los aúna a todos.

Un primer tema de interés fue el relativo a España y a la causa republicana y, más en general, la aversión hacia los fascismos. Un segundo punto de contacto puede encontrarse en una experiencia vital crucial: la experiencia de la enfermedad, en particular, de la tuberculosis ${ }^{1}$. Mostrar cómo el exilio ha sido una experiencia crucial y común en la vida de filósofos, acompañado siempre de un sentimiento de desprecio, extrañeidad en el propio mundo. Incomprensión, despojo, falta de libertad, silencio, dolor, esperanza, e intentar clarificar, sobre todo, que el exilio no se corresponde solamente con una lejanía de la propia patria, de la familia o de los amigos, sino también con todas aquellas vivencias que poseen en común la experiencia de situaciones existenciales negadas, las cuales están descritas desde la propia experiencia de vida e, incluso, que puede referirse a un estado personal del individuo respecto del mundo. Dibujar un eje transversal que dé unidad: el exilio en sus distintas formas. María Zambrano se muestra principalmente en sus obras, en concreto: Hacia un saber sobre el alma, Los bienaventurados y Carta sobre el exilio. Experiencia que muestra la importancia del exilio como lugar de revelación, describiendo cuáles son los pasos del mismo y la reivindicación que María Zambrano hace del exilio español para poder, finalmente, afirmar que el exilio es

\footnotetext{
1 Cf. E. TRAPANESE, «María Zambrano y Albert Camus: exilio y alteridad», Líneas [En ligne], Numéros en texte intégral, $7 /$ Décembre 2015 - L'existentialisme en Espagne, Partie 3 - Engagements, mis à jour le: 29/04/2017, URL: https://revues.univ-pau.fr:443/lineas/1830, 8-9-20.
} 
el lugar privilegiado para el conocimiento de sí misma y el descubrimiento de la propia patria. Reflexionar desde el sin sentido, el abandono y la soledad que suscita encontrarse fuera de la propia patria o en cualquier situación derivada del absurdo de la condición humana.

\section{El exilio como vivencia existencial en María Zambrano}

COMO PRIMER RECUERDo EL VIAJE que hacía en brazos de su padre «Quizá ya por entonces hacía yo un viaje en brazos de mi padre; un viaje que iba desde el suelo hasta la frente de mi padre. Eso ha sido decisivo para mí. Yo no podía ir ni más arriba ni más abajo. Era mi viaje, mi ir y venir» ${ }^{2}$.

Desde su nacimiento viajó de Vélez-Málaga a Madrid y un año más tarde la familia Zambrano Alarcón se traslada a Segovia, una suerte de exilio infantil que la filósofa no escogería en su vida adulta como el viaje en brazos de su padre, como el mismo exilio involuntario. La experiencia del viaje, del traslado de domicilio sin voluntad parece aproximar ya a la idea de exilio y a la idea de desgarro «esa separación de la comunidad propia que constituyen los exilios y las emigraciones» ${ }^{3}$ Podría parecer exagerada la analogía entre los cambios de domicilio a causa del trabajo del padre, de su esposo, y el exilio político, pero la no elección, la falta de voluntad del individuo en estos viajes aproximan el sentido de ambas situaciones y su significado. Su memoria en un recuerdo infantil, el del precoz viaje: «y en aquellos viajes del suelo a tan alto, debió de aprender también la distancia» ${ }^{4}$. Ese modo de aislarse del entorno, de suspender la actividad diaria, y presente estuvo en su adolescencia, juventud y más allá la imposibilidad de la relación con su primo Miguel Pizarro, el que ella afirmaría como el único amor de su vida: tres experiencias, más o menos reiterativas, que tienen en común la característica de situar al ser humano en el margen de la vida. Junto a estas y a la tradición de pensamiento a la que pertenecía su familia, otras notas biográficas valiosas para entender su concepción de exilio son la participación de la vida intelectual desde muy niña, gracias a las amistades de Blas Zambrano y también gracias al entorno de Miguel Pizarro. Esto se aúna a la experiencia política vivida en España durante los primeros cuarenta ańos del siglo XX, y por supuesto, los crímenes y exilio masivos de la población al finalizar la guerra civil española ${ }^{5}$.

\footnotetext{
${ }^{2}$ M. I. ELIZALDE FREZ, «Significados del exilio en María Zambrano», en Bajo Palabra. Revista de filosofía II Época, 7 (Madrid 2012) 487.

3 J. L. ABELLÁN, Tres figuras del desgarro: refugiado, desterrado, exiliado. Homenaje a Alain Guy (coord. J.M. Romero Baró) (Universitat de Barcelona, Barcelona 2005).

${ }^{4}$ M. ZAMBRANO, Delirio y destino (Mondadori, Madrid 1989) 25.

5 Cf. M. I. ELIZALDE FREZ, «Significados del exilio en María Zambrano», o. c., 487.
} 
Los viajes en todos los diferentes momentos de la vida ya estaban presentes, así como la enfermedad. María Zambrano contrajo la tuberculosis en 1928; no sufrió otras recaídas, pero la experiencia de la enfermedad fue para ella fundamental ${ }^{6}$. Enfermedad y vuelta a la vida que se configura como un pre-exilio, un exilio interior de quien sabe que la alteridad es parte constitutiva de nuestra existencia y que es el punto de partida trágico, para volver a nacer ${ }^{7}$.Por tanto, el exilio es una categoría fundamental para Zambrano. Exilio de una mujer, lugar de revelación que tiene unos pasos. La metodología con reivindicación del sujeto exiliado y descubrimiento de sí en el exilio para llegar a las palabras del regreso. La confesión en definitiva.

\section{El exilio de una mujer}

ESTA EXPERIENCIA DE EXILIO es el aspecto más importante a considerar en su vida y queremos dejar consignado la evolución de su pensamiento a través de dicha experiencia, recurriendo al aporte dado por la profesora especialista Juana Sánchez-Gey Venegas ${ }^{8}$ La evolución del pensamiento de María Zambrano se ubica antes del exilio en los años 1931-1939. Los primeros escritos de la autora son tres cartas que van dirigidas a su maestro Ortega y Gasset ${ }^{9}$. Las dos primeras cartas son escritas en el transcurso de 1930 y la tercera en 1932. Época que se caracteriza por la inquietud y el misterio. Espańa será el tema central de su reflexión. En este sentido, la sensibilidad es una realidad integradora desde la que se interroga por la historia y la política, pero más por el ser humano " [...] a María Zambrano le interesa sobre todo el ser del hombre, su estado, su íntimo vivir y no tan sólo su sacudida, —-se refiere a la política de esencia revolucionaria - analizando también las situaciones que conducen a la revolución. No le convencen ni el exceso de individualismo, ni los estados de rebeldía incapaces de espíritu constructivo. [...] otro sentimiento profundo, el de la religión creadora, amante de la revelación porque — la verdad sobrenatural puede ser enriquecida por el mismo que en gracioso don nos ofreció su iniciación un día», ${ }^{10}$

Desde el contexto político, Zambrano mantiene una postura crítica frente al liberalismo político del siglo XIX por ser ajeno al hombre solidario con los demás,

\footnotetext{
${ }^{6}$ Cf. E. TRAPANESE, «María Zambrano y Albert Camus: exilio y alteridad», o. c., 21.

7 Ibídem, María Zambrano: el exilio como patria

8 J. SÁNCHEZ-GEY VENEGAS, "La evolución del pensamiento en María Zambrano: Su filosofía antes del exilio (1931-1939)", en Cuadernos de pensamiento, 10 (Madrid 1996), 371-389.

9 M. ZAMBRANO, «Tres cartas de juventud a Ortega y Gasset» en Revista de Occidente, mayo 1991.

${ }^{10}$ Cf. J. SÁNCHEZ -GEY VENEGAS, «La evolución del pensamiento en María Zambrano: Su filosofía antes del exilio (1931-1939)», o. c., 376-377.
} 
manifiesta una postura en la que defiende un liberalismo que atienda por igual los campos ético, religioso y social ${ }^{11}$, encarnado en los problemas concretos del hombre de su época. En su escrito Nuevo Liberalismo, expone una experiencia de libertad como razón, más cercana a la vida y al pueblo que encarna el sentir más hondo. Cerezo, afirma que "se trata de un nuevo liberalismo que no está fundado en premisas escuetamente humanistas, sino mucho más originariamente, en la razón poética, o mejor aún en una religión cordial ${ }^{12}$. De ahí, que filosofía y vida se entrañan.

Pensamiento que va adquiriendo una fuerza ética y el acercamiento al ser humano, y que le lleva a la política, le inclinará más tarde a la filosofía. Del mismo modo si el centro de su reflexión era España, poco a poco se irá ${ }^{13}$ inclinando en torno a la vida humana y atiende al ser humano bajo un contexto histórico y político. Fruto de esta reflexión será Persona y democracia (1958). En la obra Hacia un saber sobre el alma, presenta "la razón y la pasión unidas» ${ }^{14}$, gestando una razón íntima, cotidiana y mediadora, nacida de la reconciliación y especialmente del amor y la razón, de ahí que se afirme de su razón poética que sea femenina, intuitiva, es decir, una razón que domina, que no toma represalias ${ }^{15}$ Esta filosofía significa para Zambrano revelación ${ }^{16}$ y nos enseña a hacernos cargo de nuestro ser como personas, del sentido de la vida y de los problemas que ella conlleva, por ello, afirmará: «la idea cristiana de hombre como un ser que muere y ama, que muere con la muerte y se salva con el amor ${ }^{17}$. Desea comprender y humanizar racionalmente el padecimiento, y vida que es sinónimo de tragedia. El dolor por Europa es tema central de sus reflexiones. Le interesa un pensamiento vivo que se desmarque de todo carácter cientificista. Razón que se explica estando abierta a la vida, es una forma de mirar, de carácter revelador y trascendente que configura un vivir integrado. Así la visión lleva a una forma de entender que atrae el corazón.

Escribe el artículo La metáfora del corazón ${ }^{18}$ en la que enfatiza que el corazón debe acompañar a la razón, prefigurando la razón poética que aporta un elemento salvífico que posibilita la actitud transformadora. Corazón que aporta el sentir en el que se proclama un pensar que arrastra nuestro propio $\operatorname{ser}^{19}$. Zambrano

${ }^{11}$ Cf. Ibídem, 377.

12 P. CEREZO GALÁN, «De la historia trágica a la historia ética», en Philosophica Malacitana, 4 (1991), 87.

13 P. CEREZO GALÁN, «De la historia trágica a la historia ética», en Philosophica Malacitana, 4 (1991),

1431 M. ZAMBRANO, Hacia un saber sobre el alma (Alianza Editorial, Madrid 2001) 22.

15 Cfr. J. SÁNCHEZ- GEY VENEGAS, «La evolución del pensamiento en María Zambrano: su filosofía antes del exilio (1931-1939)», o. c., 80-381.

${ }_{16}$ Cfr. M. ZAMBRANO, Hacia un saber sobre el alma, o. c., 21.

17 Ibídem., 24.

18 En Orígenes, 3 (1944) y en Hacia un saber sobre el alma, en la edición de 2000, pp. 59-69

19 J. SANCHEZ-GEY VENEGAS, «La evolución del pensamiento de María Zambrano: la primera década del exilio», en Pensamiento, Vol. 28, No 221, (mayo-agosto 2002), 228-229. 
propone el artículo La Guía ${ }^{20}$ como forma de saber que mira al otro y muestra el sentimiento de amor. La filosofía como el saber que se orienta a explicar la propia vida, de ahí que el vínculo central será la experiencia, la cual se refleja en su libro La confesión; género literario. Si «la Guía» es importante como saber de experiencia se hace necesario que ese ser humano, a quien se le dedica este saber, lo comunique desde sí mismo, desde dentro ${ }^{21}$. La trascendencia, la cual explica desde unas cualidades que caracteriza a la persona: la confianza y la esperanza. La confianza es el fondo y el principio del amor. La esperanza es puerta abierta a la trascendencia. En cuanto a la esclavitud, según Sánchez Gey, la comprende como un «anonadamiento o abajamiento para contemplar mejor la realidad del otro, porque la constante imposición del yo impide ver el tú. Desde la experiencia del anonadarse se proyecta el adentramiento en la otra realidad ${ }^{22}$. Filosofía del hombre definido como un ser capaz de crear, sońar, dueño de su destino, creado para amar, dialogar, comunicarse. Será en la segunda década de exilio en que perfila su ser como ser relacional y vislumbra que así como ella siente la soledad, «el otro, el prójimo está solo en su fondo como yo»" ${ }^{23}$, «la filosofía progresa adentrándose en las capas más profundas de la ignorancia, descubriendo problemas bajo las evidencias; criticándose a sí misma, es decir; reiterando su nacimiento. $\mathrm{Y}$ al reiterarlo lo radicaliza, ahonda en la raíz de su necesidad ${ }^{24}$.

La investigadora Ana Bundgard, nos dice que los escritos en el periodo inmediato a la guerra civil, que parecen orteguianos tanto en el enfoque teórico como en lo conceptual, no lo son, pues ya se evidencia en ellos un carácter metafísico. Así los escritos de este periodo tendrían que ser interpretados como réplica al raciovitalismo y a la circunstancialidad del yo orteguiano ${ }^{25}$.

El exilio entendido como categoría cultural ${ }^{26}$ "Vida itinerante y exilio aparecen así vinculados por un impulso trascendente que está más allá de toda circunstancia concreta ${ }^{27}$.

${ }^{20}$ «La Guía, forma de pensamiento», en Revista de las Indias, 56 (agosto 1943), 151-156; y en Hacia un saber sobre el alma, en la edición de 2000, 71-98.

${ }^{21}$ Cfr. J. SÁNCHEZ- GEY VENEGAS, «La evolución del pensamiento de María Zambrano: la primera década del exilio», o. c., 232-233.

22 Ibídem, 234.

${ }^{23}$ M. ZAMBRANO, «Adsum», en La Licorne, 5-6, (Montevideo, septiembre 1955), 76 y también en Anthropos, Suplementos 2, (marzo-abril 1987), 6.

${ }^{24}$ M. ZAMBRANO, Anthropos, Suplementos 2 (marzo-abril 1987), 17.

${ }^{25}$ Cfr. A. BUNDGARD, Más allá de la filosofía. Sobre el pensamiento filosófico-místico de María Zambrano (Trotta, Madrid 2000) 151.

26 J.L. ABELLÁN, «El exilio como categoría cultural: Implicaciones filosóficas», en Actas del V Seminario de Historia de la Filosofía española (Salamanca 1988) 43-57.

27 J.L. ABELLÁN, "María Zambrano y el exilio. Valoración de un desgarro», en Pensamiento y palabra (Segovia 2005) 61. 


\section{Lugar de revelación}

En su obra Los bienaventurados María Zambrano presenta el exilio como lugar de revelación con un papel de integrar la vida humana. Desde aquí Zambrano empieza hablar de su experiencia del exilio haciendo mención, en un primer momento, a la revelación, e inclusive se pregunta si «resultaría excesivo este término revelación, aplicado al exilio» ${ }^{28}$. Como mujer exiliada se descubre como un ser que posibilita la existencia revelándose desde su interior, importa la situación ontológica que muestra el arraigo profundo a su realidad. Constata que la revelación ha estado confinada a lo específicamente religioso y se ha explicado desde la construcción de métodos teológicos y filosóficos que apelan a una razón racionalista. Sin embargo, ella reconoce que los aportes recibidos, especialmente, por la historia de las religiones ofrecen visiones que van más allá de la razón occidental que pretende explicar, probar y justificar toda revelación ${ }^{29}$.

El pensamiento de Zambrano muestra el rechazo de una razón reducida al racionalismo desde el cual se ha entendido el mundo científico ${ }^{30} \mathrm{y}$ religioso, pero este rechazo tiene su fundamento en que para ella el racionalismo es absolutismo, el cual persigue establecer un poder para ordenar universalmente las cosas terrenas.

Así el ser humano que se rige por este tipo de razón actuará imponiendo principios que están lejos de descubrir la estructura de la realidad social, política, cultural y religiosa ${ }^{31}$. Más bien concibe la razón amplia y total con un carácter que integra, como una razón holística, da cuenta de ese todo: lo ordinario y lo extraordinario. Es así que su método razón poética es a la vez metafísico y religioso porque siempre busca ir más allá, más adentro de los límites de la realidad humana. Para María Zambrano el conocimiento que tiene el ser humano de sí mismo proviene de aquello que le falta, situación que lo dispone para ir más allá de las circunstancias ${ }^{32}$.

${ }_{28}$ M. ZAMBRANO, Los bienaventurados (Siruela, Madrid 1990) 29.

${ }^{29}$ Ibídem, 29-30.

${ }^{30}$ María Zambrano no está de acuerdo con un uso inmanentista de la razón que desde Galileo a Descartes había orientado el pensamiento científico occidental, de ahí que su propuesta es que la razón debe llegar más allá de sí misma, de un 'alguien' a otro 'alguien', de una razón de vida a una razón abierta y trascendente.

${ }^{31}$ Cf. M. ZAMBRANO, «El absolutismo y la estructura sacrificial de la sociedad», Cuadernos Revista bimestral, XLÍII (julio-agosto 1960), 63. la dimensión de lo sagrado entendida como «esa especie de placenta de donde cada especie de alma se alimenta y nutre, aun sin saberlo»

${ }^{32}$ M. ZAMBRANO, El hombre y lo divino (Fondo de Cultura Económica, México 1955) 82. 


\section{Pasos del exilio}

EL EXILIO SE DESCRIBE A TRAVÉS DE UNOS PASOS que muestran un camino existencial marcado por el dolor y la libertad. Camino que empieza a ser andado hacia una liberación humana. Pasos reflejos de la experiencia que poseen las tres figuras arquetípicas a las cuales hace alusión nuestra autora: el refugiado, el desterrado y el exiliado. Uno de los pasos que distingue por ser el principal y esencial es que «el exiliado es él mismo y a su paso, una especie de revelación que él mismo puede ignorar» ${ }^{33}$, así el exiliado refleja una existencia configurada como tránsito hacia caminos que permiten sentir la vida en su transcurrir desde las diversas situaciones límite que se vislumbran caracterizado por el padecer, el sufrir y el ignorar lo que está sucediendo. Estas situaciones constituyen su propia identidad y lo señala al afirmar que el ser exiliado es «el que no tiene figura, rostro ni máscara alguna», ${ }^{34}$ es el ser que se encuentra a la intemperie, apto para vivir en el anonimato y no ser reconocido por el mundo en que aparentemente habita. Pasos del exilio se recogen primero en el destierro que se vive como expulsión de la propia tierra, su patria su lugar primero, sin la posibilidad de encontrar otra. La situación del desterrado es de sequedad, está despierto y no sueña. Luego se transforma en refugiado quien se siente amparado, dice "acogido amorosamente en un lugar donde se le hace hueco, donde se le tolera», y, por último se da el inminente exilio ${ }^{35}$ que es el abandono total que es una «nueva patria que abraza a las demás, es una patria sin fronteras, es el centro de una patria común» ${ }^{36}$. Exiliado que ha experimentado la expulsión, la acogida y el abandono total. El exilio vivido como abandono total es a la vez el lugar donde se origina una concepción nueva del mundo, del ser humano, libre de fronteras y limitaciones, pues cualquier intento de poner límites a la realidad interna y externa al ser humano es un acto artificial, que falsea la realidad. De esta manera, se puede hablar de un pensamiento originario porque desciende a la raíz de su propio fundamento con el fin de superar los límites de la realidad ${ }^{37}$. El exilio es el espacio propicio para adentrarse en la vida que acontece con dolor y sufrimiento y desde allí acoger con sabiduría, con verdadero conocimiento, lo que es esencial a la existencia, es decir la simple vida que se va des-ocultando en la dinámica paradójica de muerte

\footnotetext{
33 M. ZAMBRANO, Los bienaventurados, o. c., 32. alguna" 51, es el ser que se encuentra a la intemperie, apto para vivir en el anonimato y no ser reconocido por el mundo en que aparentemente habita.

34 Ibídem, 34.

3552 Cf. Ibídem, 31-32, 36-37.

3653 Cf. M. ZAMBRANO, «El exilio, alba interrumpida», Revista cultural, IX 85.

3754 Cf. A. MARI, "Conocimiento y revelación», Anthropos Revista de documentación científica de la cultura, (marzo-abril 1987) 121.
} 
y resurrección pero no para eliminar la muerte, el dolor, el abandono, sino para saber permanecer en él desde la verdad ${ }^{38}$. El exiliado anda fuera de su historia, del lugar en el tiempo y el espacio donde esa historia se desarrolló y había dado sentido a su existencia. ${ }^{39}$ "Una verdad que se nos revela, una verdad a la que hemos accedido después de sobrepasar la aporta, término que significa literalmente 'sin camino', o 'camino sin salida'. Camino sin salida, efectivamente desde la razón histórica, desde el saber de la razón dominante, camino angosto, difícil de seguir, pero camino al fin que se abre ante la revelación que nos ofrece la Razón desde su nuevo sentido. Camino de un saber más íntegro, puesto que sabe de los límites, y de una idea de la razón más íntegra también». ${ }^{40} \mathrm{El}$ exiliado se vive de destierro en destierro ${ }^{41}$. , en cada destierro "el exiliado va muriendo, desposeyéndose, desenraizándose» ${ }^{42}$ y así llega el exilio verdadero al borde de una existencia carente de horizonte, sin meta ${ }^{43}$. Para ella "A medida que aminora la agonía del desamparo, cuando la esperanza se ha acallado y por tanto no ha lugar para la desesperación, y menos todavía para la exasperación, la inmensidad se va haciendo presente. La inmensidad, el ilimitado desierto, la inexistencia del horizonte y el cielo fluido. Inmensidad de la vida a la que está referido el exiliado carece de respuestas a las preguntas: cómo, por qué la partida forzosa de la propia patria, ciudad, casa, horizonte, paisaje familiar y, es aquí el punto fundamental que denota la distinción esencial entre el ser desterrado y el ser exiliado» ${ }^{44}$. El exiliado experimentará de forma dramática un sentimiento de despojo y usurpación del mundo de lo familiar, las relaciones sociales y de amistad, el medio ambiente, la geografía, la situación económica, política y cultural que dieron sentido a una identidad a partir de la construcción de un sentimiento de pertenencia, de patria, «una categoría histórica, no así la tierra ni el lugar. « La Patria es el lugar de historia, tierra donde fue sembrada un día. Y cuyo crecimiento más que el de ninguna otra historia ha sido atropellado» ${ }^{45}$. De esta forma el exiliado es el ser humano que ha sido ubicado forzosamente en otro mundo, en otra realidad espacial, temporal e inclusive existencial. Es el ser arrancado de todos sus referentes externos y se ve obligado a reconstruir el camino desde la cotidianidad y así se va reencontrando en su nueva identidad, de manera resiliente como mujer en el exilio.

\footnotetext{
38 Ibídem, 122.

39 Ibídem, 122

${ }^{40}$ M.ZAMBRANO, Los bienaventurados, o. c, 35.

41 Cf. Ibídem, 37.

42 Ibídem, 37.

43 Ibídem, 39-40.

44 Ibídem, 40.

45 Ibídem, 42.
} 


\section{Reivindicación del sujeto exiliado}

La eXPeriencia que María Zambrano tiene del exilio se describe claramente en su ensayo titulado Carta sobre el exilio ${ }^{46}$, que se configura como una reivindicación del exilio español. Es aquí donde desvela su vida de desprecio, incomprensión, despojo, silencio, dolor, esperanza y fe. La carta refleja una identidad exiliada, donde el exilio es María Zambrano. El primer destinatario es aquel que posee la virtud de hacer que se deshiele el silencio, es el ser capaz de salir de sí y de pasar a otro estado. El segundo destinatario es el que hace despertar al que yace en el silencio recobrando la palabra y la libertad. Y por último está el tercer destinatario que es el exiliado, el que se siente juzgado, llamado a dar cuentas. Es sugerente como la autora hace notar desde el sentir los rasgos que acompañan al destinatario. Carta y destinatario significan la persona que se escribe, reflejo de la propia vida de Zambrano. El exiliado es conocedor de diversas situaciones, se le ha considerado héroe y se le ha despreciado, expresando sentimientos que lo llevan y lo ubican en planos distintos de la historia. Se puede entender que el trato que recibe el exiliado está caracterizado por el desprecio y la confianza y por no reconocer su propia humanidad dentro de la historia misma. Sobre el exiliado recae toda la ambigüedad de la condición humana y la única salida es la justificación, se trata de dejar que la razón traiga sentido al sin sentido de la existencia humana, como el tomar conciencia de la vida en sus diversas dimensiones de muerte y de dolor. Al ser interrogado el exiliado debe decir verdad la que está viviendo. Dejaría a estos personajes en máscaras, la pregunta vuelve el sentido verdadero a la historia, es decir, que la respuesta la verdad que está viviendo, es posibilidad para tomar conciencia de las propias falsedades que como humanos construimos, para aparentar que estamos viviendo. Posee una verdad que está viviendo, que ha renunciado a una vida inauténtica a través de un nuevo nacimiento. Esta verdad nace y hace nacer, pero este movimiento depende del sujeto de la verdad, el sujeto siendo el exiliado muestra como su condición le exige no sólo descubrir la verdad sino descubrirse a sí mismo de ella. Consecuencia que para llegar a ser verdad es necesario padecerla en el tiempo ${ }^{47}$. El silencio de los exiliados es lo que muestra la justificación más auténtica y original y cuyo camino consiste en irse despojando de sin-razones y razones, con el único fin de quedar desnudo y desencarnado como si estuviera naciendo y muriendo. La nostalgia de la patria le viene por la irremediable inactividad a que está condenado. ¿Por qué se es exiliado? : porque la dejaron en la vida. Está en un lugar, sin nombre, saliendo de sí

\footnotetext{
${ }^{46}$ M.ZAMBRANO, "Carta sobre el exilio», Cuadernos del Congreso para la Libertad de la Cultura 49 (París, junio 1961) 65-70.

${ }^{47}$ Cf. M. ZAMBRANO, «El tiempo y la verdad», La Torre (abril-junio 1963) 112.
} 
mismo, es el habla que emite la voz que corresponde a la palabra que sale del llanto y que sale de él, ya limpia libre de pasión. Cuando el exiliado esta solo en la vida, es porque está al borde de la historia, es no estar en ella y esta situación le produce una temporalidad estática. La situación de límite entre la vida y la muerte en que se encuentra el exiliado y embebido en sí mismo, con conciencia, le permite ver cada vez con mayor claridad y precisión la propia historia, con un horizonte que carece de realidad y desde ahí es necesario extraer una cierta continuidad con el pasado, porque somos memoria y la memoria hace referencia a la coordenada temporal que la condición humana no puede ignorar y, en la cual, todo ser humano está sumergido. La memoria que es conciencia y la conciencia que es paciencia a través de los cuales puede lograr la libertad que se llevó consigo y la verdad que ha ido ganando el exiliado.

\section{Descubrimiento de sí en el exilio.}

COMO LAS PALABRAS DEL REgRESO podríamos también nombrar esta parte. No cabe duda que María Zambrano ha asumido su experiencia de exiliada como una opción configuradora de toda su vida. Su biografía interior nos habla de mujer que sabe dar nombre a las diversas situaciones que no reconocen su humanidad y las cuales envuelven el sentido de la verdad, porque es una verdad que está viviendo y que permite proyectar su existencia hacia un nuevo nacimiento. El exilio es la experiencia central de su vida. A partir de esta experiencia desde dos dimensiones temporales: un antes y un después. El antes por una vida de lucha y de compromiso desde su propio contexto: geográfico, político, religioso, cultural marcado por la inquietud y la búsqueda. El después determinado por el exilio, que se puede comprender desde dos dimensiones: la primera dimensión muestra la carga de sufrimiento, de frustración, de dolor, de tristeza, de no-ser, es el exilio que expresa todas las situaciones negadas que proceden del contexto en que vive María Zambrano, por no encontrar un espacio, un lugar donde realizar su propio ser de mujer, la pérdida de su identidad. La segunda dimensión está en la manera como ella logra tematizar con una visión esperanzadora el pesimismo y el optimismo de su propio existir. Así emprende la reconstrucción de su vida al comprender y descubrir el exilio como una opción existencial, de una toma de conciencia de las limitaciones vitales a la que siempre estuvo referida.

Recupera la dimensión positiva del exilio al concebirlo como vocación e invitación a la transparencia. Pero esto es posible porque ella es exilio, se convierte en un lenguaje propio, y este es el exilio. Ella es posibilidad de una nueva existencia, 
espacio corporal, intelectual, místico, y sobre todo espacio pensante para que el ser se rehaga de otra manera. Sentido que María Zambrano da al exilio como proyecto de vida, de salvar ese no-ser desde el ser, se constituye en posibilidad de camino, de libertad, de realización. El exilio viene a ser el espacio privilegiado donde la autora permite desvelar su ser desde el fondo que subyace de lo profundo de la existencia humana. Ella misma lo testifica cuando a su regreso del exilio afirma « [...] el exilio que me ha tocado vivir es esencial. Yo no concibo mi vida sin el exilio que he vivido, como mi patria, o como una dimensión de una patria desconocida, irrenunciable.

[...] Es una contradicción, qué le voy a hacer: amo mi exilio, será porque no lo busqué, porque no fui persiguiéndolo» ${ }^{48}$.

\section{Conclusiones}

Existe en el PENSAMiento de María Zambrano una referencia continua al tema del exilio. Tras un análisis de las obras que muestran mejor esta experiencia, entendemos que el exilio se ha configurado como una experiencia determinante para su vida y obra. La presencia de este sentimiento de extrańeza y lejanía de la patria y, en ocasiones, ruptura en el plano de las relaciones hombre-mundo acompańado de un sentimiento de desprecio, incomprensión, despojo, falta de libertad, silencio, dolor, esperanza que estaban configurando su pensamiento. Temas como el exilio, la separación y la soledad aparecen íntimamente unidos en nuestra pensadora pues se presentan como los principales obstáculos para la felicidad, acumulando casi todos los males de que sufre la humanidad. Incluso, si admitimos que la muerte, la injusticia y la violencia pueden considerarse como tipos o consecuencias de la separación, toda la desdicha humana podría resumirse aquí. La persona que quiera ser feliz en este mundo, que no quiera renunciar a la vida, en primer lugar ha de esforzarse en regresar del exilio, vencer la separación y evitar la soledad. En segundo lugar, hemos visto como la experiencia de exilio que vive María Zambrano más allá de lo meramente físico, geográfico y contextual, refleja igualmente la soledad, el distanciamiento del mundo de las apariencias y la inmersión radical en una condición de vida creativa marcada por la negación que alude misteriosamente a la experiencia del exilio interior, del ser extranjeros en la propia patria. El ser exiliado, habita entre la vida y la muerte, ambigüedad que es el lugar privilegiado para la lucidez. La persona que experimenta el exilio tiene como único refugio la interioridad, que viene a ser el lugar de la búsqueda de su ser más profundo. Así pues, la

${ }^{48}$ M. ZAMBRANO, «Amo mi exilio» (ABC, 28 de agosto 1989). 
interioridad en sentido zambraniano se puede entender como ocultamiento, más exactamente, como exilio, porque acontece en la parte de adentro del ser creatural. Ella llega a comprender la esencia del fenómeno del exilio como una categoría existencial perturbadora, pero a la vez como un ámbito privilegiado para la revelación o desvelamiento del ser, para el descubrimiento de sí misma. Como filósofa y cultivadora de una estrecha amistad y diálogo intelectual bien pueden dar cuenta de esta experiencia. Así que, el exilio ha de ser tenido en cuenta como un concepto amplio en el sentido de que no sólo indica una lejanía de la propia patria en sentido amplio.

El exilio, se expresa, igualmente y con la misma intensidad, en todas aquellas situaciones negadas que proceden del contexto en el que transcurre la vida humana por no encontrar un espacio, un lugar donde realizar nuestra propia identidad. Al hilo de nuestra reflexión, podemos poner el telón a nuestro trabajo con aquellas palabras tan ilustradoras de María Isabel Elizalde Frez en su artículo "Significados del exilio en María Zambrano".

«El viaje, la enfermedad, la mirada del otro, la nada, el despojarse, es decir, las circunstancias que separan al individuo de la vida aparentemente cotidiana forman parte de la familia conceptual de exilio como condición vital, dimensión esencial de la vida humana; o el exilio en realidad tiene que ver con todo ser humano, lo haya padecido políticamente o no. ¿¿Será el exilio una categoría perteneciente al mundo de la vida intersubjetivo aunque también perteneciente a aquello esencial que hay en la persona? ¿Será esencia del individuo sin necesidad de la oposición entre mundo y persona, el dualismo entre substancia y accidente, entre objeto y sujeto? ${ }^{49}$

Queda pues planteada la cuestión.

${ }_{49}$ M. I. ELIZALDE FREZ, «Significados del exilio en María Zambrano», o. c., 486 


\section{Referencias Bibliográficas}

\section{Obras de María Zambrano}

ZAMBRANO M., Delirio y destino (Mondadori, Madrid 1989).

El hombre y lo divino (Fondo de Cultura Económica, México 1955).

Hacia un saber sobre el alma (Alianza Editorial, Madrid 2001).

Los bienaventurados (Siruela, Madrid 1990).

«Carta sobre el exilio», Cuadernos del Congreso para la Libertad de la Cultura 49 (París 1961).

«Amo mi exilio» (ABC, 28 de agosto 1989).

«Tres cartas de juventud a Ortega y Gasset» en Revista de Occidente (1991).

«La Guía, forma de pensamiento», en Revista de las Indias 56 (1943); y en Hacia un saber sobre el alma (2000).

«Adsum», en La Licorne 5-6, (Montevideo 1955); y en Anthropos Suplementos 2 (1987).

«El exilio, alba interrumpida», Revista cultural, IX.

«El tiempo y la verdad», La Torre (1963).

\section{Bibliografía Complementaria}

Obras sobre María Zambrano y su pensamiento

ABELLÁN, J. L., María Zambrano. Una pensadora de nuestro tiempo (Anthropos, Barcelona 2006).

ABELLÁN, J. L., «Filosofía y pensamiento en el exilio: María Zambrano», en El exilio español de 1939, Vol. 3 (Taurus, Madrid 1976)

BUNDGARD A., Más allá de la filosofía. Sobre el pensamiento filosófico- místico de María Zambrano (Trotta, Madrid 2000) 
CARRÓN DE LA TORRE, A., María Zambrano y San Agustín. Diafanidad de la persona y transparencia del corazón (Universidad de Granada, Granada 2010).

EGUIZÁBAL, J. I., El exilio y el reino. En torno a María Zambrano (Huerga y Fierro Editores, Madrid 2002).

LARA, M.C. Una mirada a la carta sobre el exilio de María Zambrano. Congreso. La carta. (Facultad de Filosofía y Letras Universidad de Granada 2017) en LA CARTA Editora Universidad de Granada 2018

MARTÍN AHUMADA, J. M., La figura metafórica del exiliado en "Los bienaventurados" de María Zambrano (Universidad de Málaga, Málaga 2005).

MARTÍN AHUMADA, J. M.: "¿̨Se puede amar el exilio?», en Actas del Congreso Internacional del Centenario de María Zambrano. I Crisis y Metamorfosis de la razón (Fundación María Zambrano, Vélez-Málaga 2005).

MORENO SANZ, J., «Tres cartas de Camus a María Zambrano: breve historia de una amistad y una

publicación malogradas», en: Jesús Moreno Sanz (coord.), María Zambrano, 1904-1991: de la razón cívica a la razón poética (Amigos de la Residencia de Estudiantes, Madrid 2004).

MORENO SANZ, J., La razón en la sombra. Antología del pensamiento de María Zambrano (Siruela, Madrid 1993).

NOVOA PALACIOS, A., Elementos clave para una antropología teológica en el pensamiento filosófico de María Zambrano (Facultad de Teología de Granada, Granada 2006).

ORTEGA MUCHOZ J. F., Actas II Congreso Internacional sobre la vida y obra de María Zambrano (Fundación María Zambrano, Vélez Málaga 1998).

ORTEGA MUCHOZ J. F., Actas III Congreso Internacional sobre la vida y obra de María Zambrano: María Zambrano y la "Edad de Plata" de la cultura española (Fundación María Zambrano, Vélez-Málaga

2004).

ORTEGA MUÑOZ, J. F., María Zambrano, su vida y su obra (Conserjería de Cultura de la Junta de Andalucía, Málaga 1992).

ORTEGA MUÑOZ, J. F., Introducción al pensamiento de María Zambrano, (F.C.E., México 1994). 
PINO CAMPOS, L. M., Estudios sobre María Zambrano: el magisterio de Ortega y las raíces grecolatinas de su filosofía (Universidad de La Laguna, La Laguna 2005).

\section{Otras obras}

ABELLÁN, J. L., Tres figuras del desgarro: refugiado, desterrado, exiliado. Homenaje a Alain Guy (coord. J.M. Romero Baró) (Universitat de Barcelona, Barcelona 2005).

ABELLÁN, J. L., Historia del pensamiento español, de Séneca a nuestros días (Espasa-Calpe, Madrid 1998).

COROMINAS, J. y PASCUAL, J. A., Diccionario crítico etimológico castellano e hispánico (Gredos, Madrid 1987).

DÍAZ DÍAZ, G., Hombres y documentos de la filosofía española (CSIC, Madrid 1998).

REAL ACADEMIA ESPAÑOLA, Diccionario de la lengua española (EspasaCalpe, Madrid 1992).

Z. BAUMAN, Ética postmoderna (Siglo XXI, Buenos Aires 2004) 100.

\section{Artículos}

ABELLÁN J.L., «El exilio como categoría cultural: Implicaciones filosóficas», en Actas del V Seminario de Historia de la Filosofía española (Salamanca 1988).

ABELLÁN J.L., "María Zambrano y el exilio. Valoración de un desgarro", en Pensamiento y palabra (Segovia 2005).

AUDIN, M.L., «Le mythe de Sisyphe ou -l'autre scène», en La Revue des Lettres Modernes, Série Albert Camus 14 (1991).

BARTFELD, F., «Les paradoxes du Jonas de Camus», en The Hebrew

University Studies in Literature vol. 6, nº 1 (1978).

CEREZO GALÁN P., «De la historia trágica a la historia ética», en Philosophica Malacitana 4 (1991).

CRYLE, P., «La Peste et le monde concret: étude abstraite», en La Revue des Lettres Modernes, Série Albert Camus 8 (1977). 
DRAYTON, P., «Les Justes d'Albert Camus: une tragédie moderne?», en Selecta 10 (1989).

ELIZALDE FREZ M. I., «Significados del exilio en María Zambrano», en Bajo Palabra. Revista de

filosofía II Época 7 (Madrid 2012).

FITCH, B.T., «La Peste comme un texte qui se désigne: analyses des procédés d'autoreprésentation", en La Revue des Lettres Modernes, Série Albert Camus 8 (1976).

LÉVI-VALENSI, J., "Camus et l'Espagne», en Espagne et Algérie au Xèmesiècle. Contacts culturels et création littéraire (L'Harmattan, Paris 1985).

PIQUER A., «El tema del exilio en la obra de Albert Camus», en Anthropos, Huellas del conocimiento 199 (2003).

ROELENS, M., «Un texte, son -histoire et -l'histoire; -L'Hôte d'Albert Camus», en Revue des Sciences humaines vol.165, no 1, (1977).

SÁNCHEZ-GEY VENEGAS J., «La evolución del pensamiento en María Zambrano: Su filosofía antes del exilio (1931-1939)», en Cuadernos de pensamiento 10 (Madrid 1996).

SANCHEZ-GEY VENEGAS J., «La evolución del pensamiento de María Zambrano: la primera década del exilio", en Pensamiento Vol. 28, no 221 (2002).

TRAPANESE, E., «María Zambrano y Albert Camus: exilio y alteridad», Líneas [En ligne], Numéros en texte intégral, 7/ Décembre 2015- L’existentialisme en Espagne, Partie 3 - Engagements, mis à jour le: 29/04/2017.

TUDORAS L. E., Extrañeidad y exilio interior en dos relatos de Albert Camus: -la femme adultère y -Jonas ou l'artiste au travail, Revista de Filología Románica VII (2011).

DOI: https://doi.org/10.15366/bp.2020.24.003

Bajo Palabra. II Época. No 24. Pgs: 55-72 